\title{
Deconstruction on a Tradition: The Image of Hermit From "Gathering Vetch" in Old Tales Retold
}

\begin{abstract}
ZENG Yan
Southwest University, Chongqing, China

For thousands of years, Bo Yi and Shu Qi are always the hermit models who are familiar to most Chinese intellectuals in different ages of China. The hermit in "Gathering Vetch" written by LU Xun is one that is caught in a humiliated life, rather than being lofty and great. He has changed the reader's thoughts on the traditional image of hermits. The hermit in Old Tales Retold is humiliated and weak, destroying the traditional image, which reflects LU Xun's spirit of suspicious and sympathy on hermit and also reveals spectators' indifference and critique on the old China's social reality. LU Xun has kept the passion for fight.
\end{abstract}

Keywords: Bo Yi, Shu Qi, image of the hermit

\section{Introduction}

For thousands of years, Bo Yi and Shu Qi are always the hermit models who are familiar to most Chinese intellectuals in different ages of China. Their stories are described in Records of the Historian Biography of Bo Yi and Shu Qi. Bo Yi and Shu Qi are sons of monarch of Gu Zhu State in the end of Shang Dynasty. The father appoints Shu Qi as heir to the throne, but Shu Qi is willing to give the throne to his elder brother Bo Yi and Bo Yi refuses. So both of them give up the throne and go to King Wu of Zhou for shelter. When King Wu attacks Zhou, Bo Yi and Shu Qi dissuade him. After the fall of Shang Dynasty, Bo Yi and Shu Qi live in seclusion in Mount Shouyang, do not eat grains of Zhou Dynasty, feeding on vetch, and finally starve to death on Mount Shouyang. The hermit image of Bo Yi and Shu Qi shaped in traditional classic books is very holy and is regarded as the model of sticking to their own integrity. In order to insist on morality and justice, they give up high position and great wealth and choose to live on mountain in seclusion, far away from earthliness. For thousands of years, they are the models of sticking to integrity, composing a paean of the hero of morality for people. However, the image of Bo Yi and Shu Qi in Old Tales Retold written by LU Xun is totally complete opposite of original hermit image in people's minds. They are caught in daily life, having no way to live, being humble and weak before power and being insignificance before spectators. This kind of image refreshes the understanding of hermit in public readers' minds.

\section{The Image of Hermit of Bo Yi and Shu Qi}

First, in Old Tales Retold, two hermits are worried about "having foods". Bo Yi and Shu Qi have to meet

ZENG Yan, Ph.D. candidate, Department of Literature, Southwest University. 
with the problem of livelihood because being full can make them survive. Based on this, pancake is mentioned many times in texts. "Pancake is becoming smaller and smaller" (LU, 2005c, p. 409); "Pancake is not only becoming smaller but also the flour worse" (LU, 2005c, p. 409); "Maybe sometimes ten piece of pancakes are made" (LU, 2005c, p. 410); "It takes time to make 103 or 104 pieces of pancakes" (LU, 2005c, p. 412). LU Xun restores the hermit's dilemma, because as ordinary people, "eating" is the primary factor for survival. For Bo Yi and Shu Qi, time can be connected with making pancake, which indicates that they are so familiar with the time of making the pancake and they are expending their lives in the course of waiting for eating. They have pancake in nursing home and they have "begging foods" (LU, 2005c, p. 419) as the last supper before escaping to Mount Shouyang. On the mountain, they "think of Tuckahoe" (LU, 2005c, p. 420), but Shu Qi can not find Tuckahoe eventually. Bo Yi "is hungry and the stomach gurgles" (LU, 2005c, p. 420) and at last they have to find out something to stratify their hunger, "vetch soup, vetch sauce, vetch boiled in clear soup, braised vetch and dry vetch in the sun" (LU, 2005c, p. 422). Their problem of livelihood gets relieved temporarily. Bo Yi and Shu Qi insist on traditional morality and justice but have to be worried about basic living requirements. In Plucking, they are worried about hungry day and night rather than being far away from reality. They are struggle for their life, just as the same with ordinary people.

Secondly, hermit is humble and weak before people in power. The hermit advance bravely sticking to their morality and justice. Before King Wu of Zhou, they give their advice at the cost of death, while it can not draw attention from people in power and they are pushed away by warriors. The last dignity of hermit is trampled completely. Before "people advocating force", Bo Yi and Shu Qi "just shout 'Ah', stumble for 3.3 meters and then fall down on the ground" (LU, 2005c, p. 412). They encounter robbery and fear to "tremble" (LU, 2005c, p. 418). They are afraid of their life at first when they find out that brigands are disappointed because of robbing nothing. At last, brigands "pay attention to Bo Yi's tremble" (LU, 2005c, p. 418), despise their poverty and weakness, so brigands decide to let them go. The hermit is in an extremely awkward position again before "people advocating force". Descriptions are as follows "Bo Yi has nothing to answer and even has no time to wear cloth well and then run with long strides with Shu Qi" (LU, 2005c, p. 419). Like the ordinary people, they are in panic before danger rather than being fearless. The hermit of spirit is worthless before "people advocating force".

At last, hermit is regarded as a disparate person and dies in desperate and lonely. Bo Yi and Shu Qi struggle between survival and morality, but their behavior is not understood by spectators. "The woodcutter accidentally finds out Bo Yi and Shu Qi die in the cavern behind the mountain" (LU, 2005c, p. 425). However, what he cares about is not the two people's death, but "there is no sheepskin furred robe under them and where is it" (LU, 2005c, p. 425). "Once the message spreads to the village, a large number of people come to see, one after another till to the night" (LU, 2005c, p. 425). Suddenly, the death of hermit becomes topic of dinner conversation of spectators. Just as the text writes "when people talk about the hermit's death in summer night, someone say they die of old age; some say of illness and some say they are killed by robber who robs the furred robe" (LU, 2005c, p. 426). After they die, a large crowds go to see them and later no one to see. To get psychological comfort, spectators reach the consensus that the death of Bo Yi and Shu Qi is an act of providence. "God also hates their greedy" (LU, 2005c, p. 426). The reason for their death is that God can not tolerate the two disparate persons. Spectators think everything is attributed to God, so they can "feel relaxed" (LU, 2005c, p. 426). From watching the strange to 
gossip and to spectators' finding reasons for themselves, the description which is of relaxed style reflects the cruel social reality. People are shocked by spectators' numbness. What happens to others is just like a farce, which can not draw spectators' sympathy and even they choose to forget. The sacrifice of hermits is worthless. LU Xun once evaluates the indifference on meaningless sacrifice of people as "blood of the hero is always salt for people of indifferent country and even for idlers" (LU, 2005e, p. 317).

In a word, faced with life, power and spectators, traditional hermit is disconnected with time and can not adapt to society, so the value of sticking to morality and justice is worthless. In spectators' opinion, hermit is not lofty any more, but just as the topic of dinner conversation.

\section{Writer's Attitude}

The author changes traditional hermit image on purpose. First, hermit is trapped in the plight of life, worried about trivial matters day and night. By LU Xun's description, two sages are not holy. They live life by counting the pancake and they are incompetent and weak before warriors and brigands. Taking off the holy veil of two hermits, human's servile nature is revealed before public. Therefore, ideal and faith seem pale and weak before reality and the contradiction between morality and human nature reveals completely. LU Xun, being suspicious, analyzes issue comprehensively and profoundly and he once says "when analyzing the problem, I am too careful to doubt, so I can not go forward bravely" (LU, 2005b, p. 33). This kind of life attitude makes a profound influence in his artistic creation. By writing the hermit, LU Xun asks a question to readers that what value of the standard moral is when people cannot meet their basic requirements if insisting on morality and so called "etiquette". What is meaning of life if people have to change their nature without sticking to standard moral? When people become the tool without human nature, author doubts the ultimate value of "live just for live". Thus LU Xun not only objectively evaluates the special function of Confucian culture in Chinese culture but also reveals appropriately the internal paradox.

Secondly, guardian for pure faith has no fear of power. Bo Yi and Shu Qi "present the plight and bitter experience that purist has before historical reality"(ZHANG, 2012, p. 48). There is a confrontation between unique and disparate people and vulgar people in the text, which shows LU Xun's appreciation and sympathy on hermit's "facing with life bravely" and conceals the author's satire on false revolutionists. The hermit is the representative of the outdated and feudal in others' eyes but it does not mean the revolutionaries are not feudal representative. The revolutionary such as XIAO Bing-jun in the text should be suspected about their revolution will. During May Fourth Period, people have high passion for revolution while LU Xun is always suspicious and think the revolution in another way. He thinks what revolutionary should do after revolution and pays attention to "day after the revolution" (Bell, 1996, p. 29), "when the mundane world again intrude upon consciousness" (Bell, 1996, p. 29), does the revolutionary obey the kingly way or is a kind of force? In the text, King Wu of Zhou "sends armed forces according to the God" to rebuild a new social order. King Wu of Zhou obeys the kingly way, while King of Shang rules by force. However, Lu Xun evaluates to the point that,

The kingly way in China which seems the opposite against the force is the brother with force in fact. Why people sing the praise of it is that people hope the ruler can use less force or even no force. (LU, 2005a, pp. 10-11)

At the beginning of King of Zhou sending armed force, "Bo Yi and Shu Qi try their best to dissuade, but it 
fails. The force of Shang also resists and insists the battle. Then people of Yin rebels and they are called 'disloyal citizens'. However, there seems something wrong” (LU, 2005a, pp. 10-11). Are Bo Yi and Shu Qi revolutionaries? Is the revolution force King of Wu or King of Zhou? Revolutionary and false revolutionary are full of the tide of revolution and the complex makes people dazzling. However, people become tool who has no opinion. Once it appears people such as Bo Yi and Shu Qi, spectators can not understand them and two hermits who insist their position are regarded as a joke by people. In LU Xun's opinion, the destiny of Bo Yi and Shu Qi is miserable mingled with the author's sympathy. Meanwhile they are tragic mixed with the author's doubt on new time enlightenment. WANG Xiao-ming has said "Lu Xun has his special opinion reflecting his confidence in enlightenment. Compared with others, he can see some worse aspects of China's future”(WANG, 1993, p. 60). In LU Xun's artistic creation, he expresses his unique view of enlightenment.

At last, taking Bo Yi and Shu Qi as reference, it embodies spectators' indifference. For the death of hermit, "just like it puts some salt into the sea of people, though it makes people feel a little taste, people still feel tasteless" (LU, 2005d, p. 343). The death of Bo Yi and Shu Qi is just the topic of conversation for spectators and is forgotten gradually by people. The similar scene is so familiar for readers. In Kung I-chi, a band of idle "spectators" in Xian Heng wine shop not only laugh at other's suffering, but also use it to enrich their internal empty. In Publicly Expose, men and women are watching the prisoner, but they do not know maybe one day they will be the prisoners to be watched by others. LU Xun is rage once again, making "shout" for national character. Plucking shows the appalling picture for people by mild style. The deep-rooted bad character of people is the obstacle of social progress and the author shouts from the bottom of his heart to warn national people that if being indifference, victims are others today but maybe it is your turn tomorrow.

\section{Conclusion}

In a word, the hermit in Old Tales Retold is humiliated and weak, destroying the traditional image, which reflects LU Xun's spirit of suspicious and sympathy on hermit and also reveals spectators' indifference and critique on old China's social reality. LU Xun has kept the passion for fight. In his unique artistic creation, "he 'does not make the past as history' but 'uses the death to stimulate modern people to hate and love. Combining the past and the modern, we can understand it but it is hard for us to learn well' " (MAO, 1984, p. 137).

\section{References}

Bell, D. (1996). The cultural contradictions of capitalism. New York: Basic Books.

LU, X. (2005a). A few stories about China: Demi-concession studio essays. In The complete works of LU Xun (Vol. 6). People's Literature Publishing House.

LU, X. (2005b). Letters between LU Xun and XU Guang-ping, Collection I. In The complete works of LU Xun (Vol. 11). Beijing: People's Literature Publishing House.

LU, X. (2005c). "Gathering Vetch” from Old Tales Retold. In The complete works of LU Xun (Vol. 2). Beijing: People's Literature Publishing House.

LU, X. (2005d). On gossip is a fearful thing. In The complete works of LU Xun (Vol. 6). Beijing: People's Literature Publishing House.

LU, X. (2005e). Prologue to waves that fight for freedom: Collected works that not included in anthologies. In The complete works of LU Xun (Vol. 7). People's Literature Publishing House.

MAO, D. (1984). Xuanwu gate incident: Old tales retold research materials. G. L. MENG (Ed.). Shandong: Shandong Fine Arts Publishing House. 
WANG, X. M. (1993). The life that can hardly be faced directly—Bibliography of LU Xun. Shanghai: Shanghai Literature and Art Publishing House.

ZHAHG, F. (2012). Extremely natural and necessary exaggeration: The translation of liberated Don Quixote and Gathering Vetch. Luxun Research Monthly, 12. 